\title{
The Role of Pancreatic Alpha Cells and Endothelial Cells in the Reduction of Oxidative Stress in Pseudoislets
}

\author{
Fredrik C. Wieland ${ }^{1}$, Mireille M.J.P.E. Sthijns ${ }^{1,2}$, Thomas Geuens ${ }^{1}$, \\ Clemens A. van Blitterswijk ${ }^{1}$ and Vanessa L.S. LaPointe ${ }^{1 *}$ \\ ${ }^{1}$ MERLN Institute for Technology-Inspired Regenerative Medicine, Maastricht University, Maastricht, Netherlands, ${ }^{2}$ Centre for \\ Healthy Eating and Food Innovation, Maastricht University, Maastricht, Netherlands
}

\section{OPEN ACCESS}

Edited by:

Guangdong Zhou,

Shanghai Jiao Tong University, China

Reviewed by:

Roberto Gramignoli,

Karolinska Institutet (KI), Sweden

Giovanni Vozzi,

University of Pisa, Italy

*Correspondence:

Vanessa L.S. LaPointe

v.lapointe@maastrichtuniversity.nl

Specialty section:

This article was submitted to

Tissue Engineering and Regenerative

Medicine,

a section of the journal

Frontiers in Bioengineering and

Biotechnology

Received: 22 June 2021

Accepted: 19 August 2021

Published: 09 September 2021

Citation:

Wieland FC, Sthijns MMJPE, Geuens T, van Blitterswijk $C A$ and LaPointe VLS (2021) The Role of

Pancreatic Alpha Cells and Endothelial

Cells in the Reduction of Oxidative

Stress in Pseudoislets.

Front. Bioeng. Biotechnol. 9:729057.

doi: 10.3389/fbioe.2021.729057
Pancreatic beta cells have inadequate levels of antioxidant enzymes, and the damage induced by oxidative stress poses a challenge for their use in a therapy for patients with type 1 diabetes. It is known that the interaction of the pancreatic endocrine cells with support cells can improve their survival and lead to less vulnerability to oxidative stress. Here we investigated alpha (alpha TC-1), beta (INS1E) and endothelial (HUVEC) cells assembled into aggregates known as pseudoislets as a model of the pancreatic islets of Langerhans. We hypothesised that the coculture of alpha, beta and endothelial cells would be protective against oxidative stress. First, we showed that adding endothelial cells decreased the percentage of oxidative stress-positive cells. We then asked if the number of endothelial cells or the size (number of cells) of the pseudoislet could increase the protection against oxidative stress. However, no additional benefit was observed by those changes. On the other hand, we identified a potential supportive effect of the alpha cells in reducing oxidative stress in beta and endothelial cells. We were able to link this to the incretin glucagon-like peptide-1 (GLP-1) by showing that the absence of alpha cells in the pseudoislet caused increased oxidative stress, but the addition of GLP-1 could restore this. Together, these results provide important insights into the roles of alpha and endothelial cells in protecting against oxidative stress.

Keywords: GLP-1 - glucagon-like peptide-1, INS1E cells, HUVEC - human umbilical vein endothelial cell line, oxidative stress, pseudoislet, ROS - reactive oxygen species, alpha TC1 clone 6

\section{INTRODUCTION}

Diabetes mellitus type 1 is an autoimmune disease that results in the depletion of pancreatic beta $(\beta)$ cells that produce insulin to regulate glucose uptake. The pancreatic tissue is one of the most metabolically active tissues within the human body, and especially the $\beta$ cells at elevated glucose concentrations rely on oxidative metabolism for adenosine triphosphate synthesis (Bakker et al., 2000). To illustrate this, the islets of Langerhans receive up to $10 \%$ of the pancreas' blood supply, but only occupy $1-2 \%$ of its volume (Myasnikova et al., 2019).

The result of the high metabolic activity of the pancreatic islets is the generation of by-products such as reactive oxygen species (ROS) by mitochondrial respiration during glucose stimulation (Gerber and Rutter, 2017). An antioxidant defense can be generated by glutathione and vitamin E, as well as with antioxidant enzymes such as superoxide dismutase, catalase, and peroxiredoxins to counteract the formation of ROS. The $\beta$ cells are notably vulnerable to damage induced by oxidative stress as they have inadequate levels of antioxidant enzymes (Haskins et al., 2003; Stancill et al., 2019). 
A number of studies suggest an association between endothelial cell incorporation in islets and the cells' resilience to oxidative stress and improved viability and function (Skrzypek et al., 2018). Endothelial cells are important in establishing the islets of Langerhans' vasculature (Ballian and Brunicardi, 2007; Berclaz et al., 2016) and they provide extracellular matrix (ECM) components such as type IV collagen and laminins and growth factors that improve $\beta$ cell insulin secretion (Olerud et al., 2011; Figliolini et al., 2014; Komatsu et al., 2017). To understand why supporting cells positively affect endocrine cells, observational studies of their spatial arrangement and interactions have been performed. For example, it has been shown that $\beta$ cells are typically located near endothelial or alpha $(\alpha)$ cells (Bosco et al., 2010; Wieland et al., 2020). This localization of $\beta$ cells is associated with functional improvement and can be linked to increased antioxidant protection provided by the $\alpha$ or endothelial cells. Therefore, we were interested to understand if the endothelial or $\alpha$ cells protect against oxidative stress in islets.

There is also a close functional relationship between $\alpha$ and $\beta$ cells that is affected by oxidative stress. Their hormones, insulin and glucagon, counteract each other, where high blood glucose concentration stimulates $\beta$ cells to secrete insulin and suppresses glucagon secretion from the $\alpha$ cells (Xu et al., 2006). The $\alpha$ cells also secrete an incretin, glucagon-like peptide 1 (GLP-1), upon the stimulus of insulin or high glucose concentration (Liu et al., 2018). High glucose, inflammation and oxidative stress have an effect on GLP-1 production. Normally glucagon is a product of the proglucagon protein cleavage by the enzyme proconvertase 2 (PC2), but stress causes a change in the cleavage of proglucagon by activating the enzyme proconvertase $1 / 3(\mathrm{PC} 1 / 3)$, which results in the product GLP-1 (Sancho et al., 2017). In turn, GLP-1 reduces endoplasmic reticulum stress and autophagy in endothelial cells and improves the antioxidant capacity in $\beta$ cells (Ishibashi et al., 2010; Schisano et al., 2012; Fernández-Millán et al., 2016; Cai et al., 2018).

This study set out to assess the roles of $\alpha$ and endothelial cells in protecting bioengineered islets against oxidative stress. To do this, we made use of the well-established lines of $\alpha$ (alpha TC-1), $\beta$ (INS1E) and endothelial (HUVEC) cells that we aggregated in a three-dimensional suspension to form a pseudoislet. This model confers the possibility to control the pseudoislet composition, allowing us to assess the impact of the $\alpha$ and endothelial cells on ROS levels, which we did by including or excluding them from the pseudoislet. In the same fashion, we challenged the pseudoislet composition by changing its size (number of cells) or tuning the ratio of endothelial cells. Finally, we investigated the impact of GLP-1 in oxidative stress and showed the important role for $\alpha$ cell. The work presented here provides new understanding of the supportive role of $\alpha$ and endothelial cells in reducing the oxidative stress in the pseudoislet, which can be taken into account in the future development of bioengineered islets.

\section{METHODS AND MATERIAL}

\section{Cell Culture}

Alpha TC1 clone 6 (Cat\# CRL-2934 ATCC, Manassas, United States), referred to as $\alpha$ cells, were cultured in DMEM
6046 (Sigma-Aldrich) supplemented with 10\% (vol/vol) FBS (Sigma-Aldrich), $15 \mathrm{mM}$ HEPES, $0.1 \mathrm{mM}$ non-essential amino acids, $1.5 \%$ (wt/vol) sodium bicarbonate and 2.0\% (wt/vol) glucose. INS-1E (AddexBio, San Diego, United States), referred to as $\beta$ cells, were cultured in RPMI 1640 (Gibco) supplemented with $1 \mathrm{mM}$ sodium pyruvate, $0.05 \mathrm{mM}$ 2-mercaptoethanol, $10 \mathrm{mM}$ HEPES, and 5\% (vol/vol) FBS. Human umbilical vein endothelial cells (HUVECs) (C2519A, Lonza, Maryland, United States; used at passage 5) were cultivated in EGM-2 (PromoCell). All cells were cultured under a humidified atmosphere with $5 \% \quad \mathrm{CO}_{2}$ at $37^{\circ} \mathrm{C}$ and negative for mycoplasma contamination (Mycoplasma Detection Kit, \#B39035, BioTool).

\section{Creation of Constructs and Stable Cell Lines}

The open reading frames of $\mathrm{mTagBFP} 2$ and $\mathrm{mNeongreen} 2$ were amplified by PCR from donor vectors pBAD-mTagBFP2 (Addgene, \#34632) and pSFFV_mNG2 (11)1-10 (Addgene, \#82610) respectively, and ligated in a pLenti6.2 destination vector. Both vectors were verified by Sanger sequencing and deposited to Addgene as pLenti6.2_mTagBFP2 (\#113725) and pLenti6.2_mNeonGreen2 (\#113727).

Stable cell lines were generated using the lentiviral transduction of $\alpha$ cells and $\beta$ cells using pLenti6.2_mTagBFP2 and pLenti6.2_mNeonGreen2, respectively. Both plasmids were co-transfected separately with third-generation lentiviral packaging and envelope vectors [pMD2. G (Addgene, \#12259), pRSV-Rev (Addgene, \#12253), and pMDLg/pRRE (Addgene, $\# 12251$ ] ] into HEK-293T cells using the PEIpro (VWR) transfection reagent. After $24 \mathrm{~h}$, the viral supernatant was collected and used to transduce $\alpha$ and $\beta$ cells. Positive cells were selected $48 \mathrm{~h}$ after transduction using $1 \mu \mathrm{g} / \mathrm{ml}$ puromycin dihydrochloride (Sigma-Aldrich) added to growth media for at least 7 days. Transduction efficiency was assessed by fluorescence microscopy after a minimal culture period of 7 days.

\section{Stable Cell Line Purification by Using Fluorescence-Activated Cell Sorting}

In order to purify the $\alpha$-BFP 2 and $\beta$-mNeonGreen 2 cells, a BD FACSAria III equipped with a $100 \mu \mathrm{m}$ flow tip facilitated the sorting of the cells. Untransfected cells were used as an autofluorescence control. The cells were sorted in PBS supplemented with $10 \%$ (vol/vol) FBS (Sigma-Aldrich). Debris was excluded by gating on the physical parameter (FSC-A/SSC), followed by excluding doublets using pulse processing (FSC-H vs FSC-A). Sorted cells were collected in a $15 \mathrm{ml}$ tube with $3 \mathrm{ml}$ of culture medium.

\section{Pseudoislet Formation}

Prior to cell seeding, the wells were washed twice with modified EGM-2 medium supplemented with a final concentration of $10 \mathrm{mM}$ HEPES, $1 \mathrm{mM}$ sodium pyruvate, $0.1 \mathrm{mM}$ non-essential amino acids, 2\% (wt/vol) glucose and $0.05 \mathrm{mM} \mathrm{2-}$ 
mercaptoethanol. Cell number was determined by trypan blue exclusion on an automated cell counter (TC20, Bio-Rad Laboratories). In order to form pseudoislets, which are threedimensional aggregates of $\alpha, \beta$ and endothelial cells, the cells were trypsinised with $0.05 \%$ trypsin-EDTA for $5 \mathrm{~min}$ at $37^{\circ} \mathrm{C}$. Subsequently, the cells seeded either in a 24-well AggreWell 400 plate (STEMCELL Technologies) to generate 1,200 pseudoislets/well or in a 96-well round-bottom plate (Corning Elplasia) for 79 pseudoislets/well. As a basis, all pseudoislets had a total of 1,500 cells, but their composition had the varying ratios of

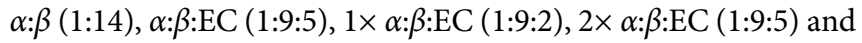
$4 \times \alpha: \beta: E C \quad(1: 9: 20)$. When studying the different sizes of pseudoislets, the ratio of $\alpha: \beta:$ EC of $1: 9: 5$ was used with the different total number of 750, 1,500 and 3,000 cells. All cell types were seeded simultaneously into the microwell array, which was then centrifuged at $200 \times \mathrm{g}$ for $4 \mathrm{~min}$ to distribute the seeded cells into the microwells evenly. The pseudoislets were cultured for up to 5 days in a modified EGM-2 medium, with the medium refreshed daily.

\section{ROS Assay}

To induce oxidative stress, the pseudoislets were incubated with $250 \mu \mathrm{M}$ hydrogen peroxide $\left(\mathrm{H}_{2} \mathrm{O}_{2}\right)$ diluted in phenol-free EGM-2 (PromoCell) after being washed with PBS for $2 \mathrm{~min}$. After $30 \mathrm{~min}$ incubation in $\mathrm{H}_{2} \mathrm{O}_{2}, 10 \mu \mathrm{M}$ of the fluorogenic probe CellROX Deep Red Reagent (Invitrogen) in phenol-free EGM-2 with/ without $250 \mu \mathrm{M} \mathrm{H}_{2} \mathrm{O}_{2}$, was added into the existing medium to a final concentration of $5 \mu \mathrm{M}$. Control samples were incubated with phenol-free EGM-2 for $60 \mathrm{~min}$ at $37^{\circ} \mathrm{C}$. After $30 \mathrm{~min}$ of incubation with CellROX Deep Red Reagent, the pseudoislets were fixated in $4 \%$ (wt/vol) formaldehyde diluted in PBS for $20 \mathrm{~min}$ at room temperature and were subsequently, washed two times with PBS for 3 min.

\section{Glucagon Like-Peptide 1}

The glucagon-like peptide-1 (GLP-1) agonist, liraglutide (Abcam), was prepared in the modified EGM-2 at a final concentration of $100 \mathrm{nM}$. It was pre-incubated with the pseudoislet for $2 \mathrm{~h}$ under a humidified atmosphere with 5\% $\mathrm{CO}_{2}$ at $37^{\circ} \mathrm{C}$. In the ROS assay, the condition with GLP-1 preincubation had $100 \mathrm{nM}$ GLP-1 agonist included in the phenolfree EGM-2 media with $250 \mu \mathrm{M} \mathrm{H}_{2} \mathrm{O}_{2}$.

\section{Analysis to Identify ROS Positive Cells}

The pseudoislets were incubated with $5 \mu \mathrm{M}$ SYTOX Orange nucleic acid stain (Invitrogen) diluted in PBS for $30 \mathrm{~min}$ followed by two washes with PBS. They were gently flushed out of the microwell arrays into the CELLview dish (Greiner Bio-One) and mounted with ProLong Gold (Invitrogen). To identify ROS-positive cells, optical sections (z-stacks; $60-90 \mu \mathrm{m}$ into the depth of the pseudoislet) were obtained on a Nikon Eclipse Ti-E inverted microscope equipped with a 40×/1.3 NA immersive oil objective (Nikon Instruments) and spinning disc X-Light2 (CrestOptics).

Cell identification and quantification was done using Imaris 9.7.0 (Bitplane, South Windsor, CT, United States). Images were automatically reconstructed into $3 \mathrm{D}$ visualisations and the "spot" tool identified the nuclei using SYTOX Orange with an estimated diameter set to $6 \mu \mathrm{m}$ and a manual threshold setting. To quantify $\alpha$ cells with BFP2 (Ex $\lambda 399 \mathrm{~nm}$ and Em $\lambda 454 \mathrm{~nm}$ ), the "surface" tool was applied followed with the parameters: $12 \mu \mathrm{m}$ diameter of largest sphere, $10 \mu \mathrm{m}$ split touching objects, and a manual threshold setting. To quantify $\beta$ cells with mNeonGreen 2 (Ex $\lambda 506 \mathrm{~nm}$ and Em $\lambda$ $517 \mathrm{~nm})$, the "surface" tool was applied followed with the parameters: $16 \mu \mathrm{m}$ diameter of largest sphere, $8 \mu \mathrm{m}$ split touching objects, and a manual threshold setting. To identify ROS-positive cells with CellROX Deep Red (Ex $\lambda 644 \mathrm{~nm}$ and $\operatorname{Em} \lambda 665 \mathrm{~nm}$ ), the "surface" tool was applied with a threshold set using the control samples. To quantify the number of positive nuclei with oxidative stress, the function "shortest distance to surfaces" was used to identify a nucleus within $5 \mu \mathrm{m}$ distance (in the planes of xyz) to ROS. To count ROS-positive $\alpha$ and $\beta$ cells, the function "shortest distance to surfaces" was used and cells were considered positive when the distance of the cells' surface was within $1 \mu \mathrm{m}$ to the ROS dye. Any manual threshold settings were kept constant in all experiments.

\section{Statistical Analysis}

Data were reported as means \pm SEM from three to four independent experiments $(\mathrm{N}=3-4)$, each of which included a set of $10-16$ pseudoislets $(n=10-16)$. Statistical analysis was done in Prism software (GraphPad, version 8.1, La Jolla, CA, United States), with significance determined by a 2-way ANOVA with Holm-Šidák's multiple comparison test when $p \leq 0.05$.

\section{RESULTS}

\section{The Addition of Endothelial Cells in the Pseudoislet Reduces the Oxidative Stress in $\alpha$ and $\beta$ Cells}

In order to describe the role that endothelial cells play in the response of pseudoislets to oxidative stress induced by $\mathrm{H}_{2} \mathrm{O}_{2}$, we formed two types of pseudoislets. The first comprising $7 \% \alpha$ cells and $93 \% \beta$ cells and the second comprising $7 \% \alpha$ cells, $60 \% \beta$ cells, and $33 \%$ endothelial cells. All pseudoislets contained approximately 1,500 cells. After 5 days in culture, oxidative stress was induced by the addition of $\mathrm{H}_{2} \mathrm{O}_{2}$ for $1 \mathrm{~h}$, after which the cells were labeled with a fluorescent probe (CellROX Deep Red Reagent) for detection of oxidative stress (Figures 1A-D). Overall, the addition of endothelial cells to the pseudoislet had a protective effect against oxidative stress.

By adding endothelial cells to the pseudoislet, the percentage of oxidative stress-positive cells incubated with $\mathrm{H}_{2} \mathrm{O}_{2}$ was not significantly higher than the control condition without $\mathrm{H}_{2} \mathrm{O}_{2}$ (Figure 1E). When the pseudoislets were exposed to $250 \mu \mathrm{M}$ $\mathrm{H}_{2} \mathrm{O}_{2}$, the presence of endothelial cells reduced the total percentage of cells positive for oxidative stress from 7.6 to $3.6 \%(p<0.001$; Figure 1E; N:3, n:12).

We then wanted to determine how $\alpha$ and $\beta$ cells responded to the induction of oxidative stress and how this was affected by including endothelial cells. Looking at the $\alpha$ cells, we found that $15.1-17.6 \%$ were already positive for oxidative stress in the basal condition without $\mathrm{H}_{2} \mathrm{O}_{2}$, and this was unaffected by the presence of endothelial cells (Figure 1F; N:3, n:12). However, when oxidative stress was 

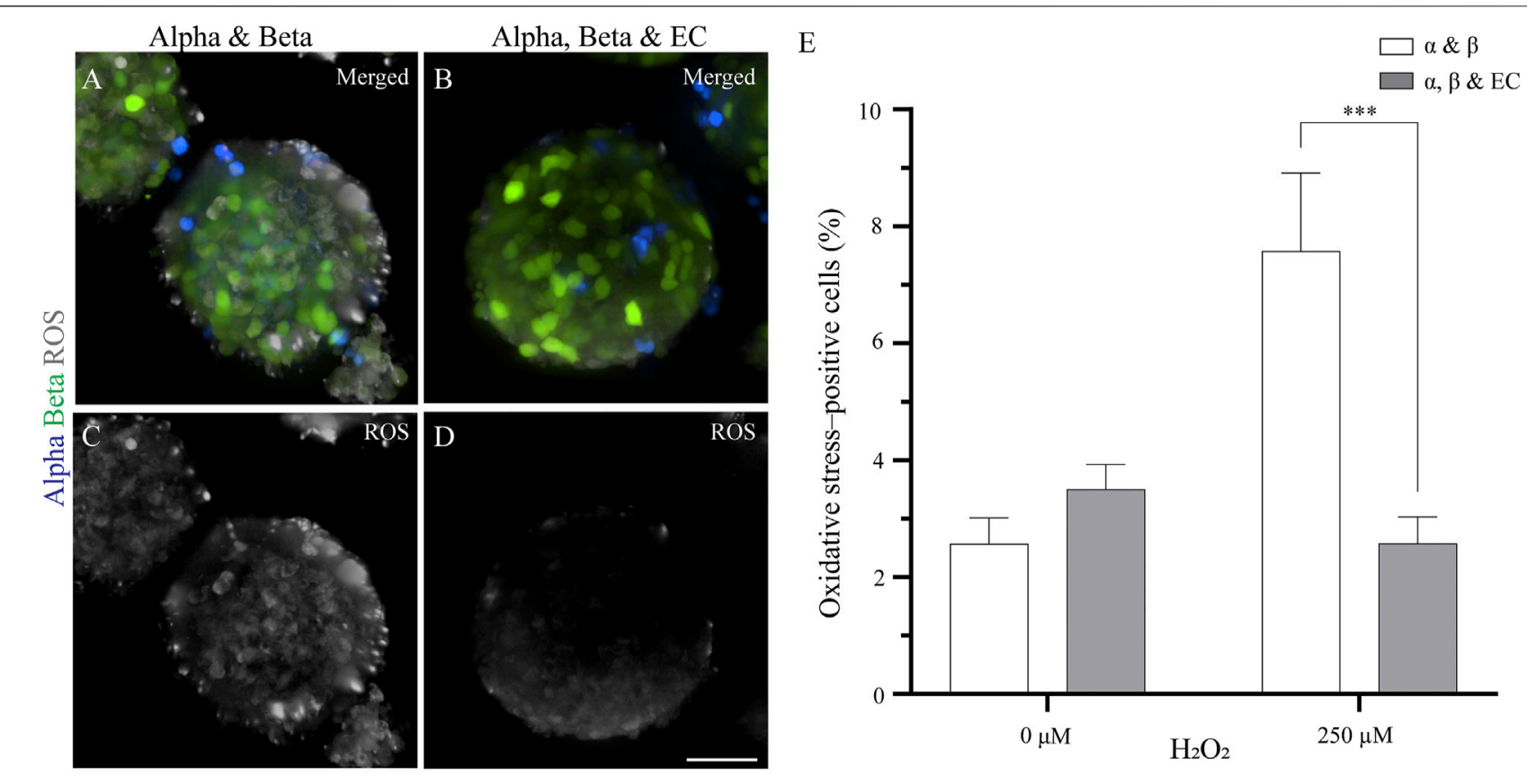

F

$\square \& \beta \quad G$
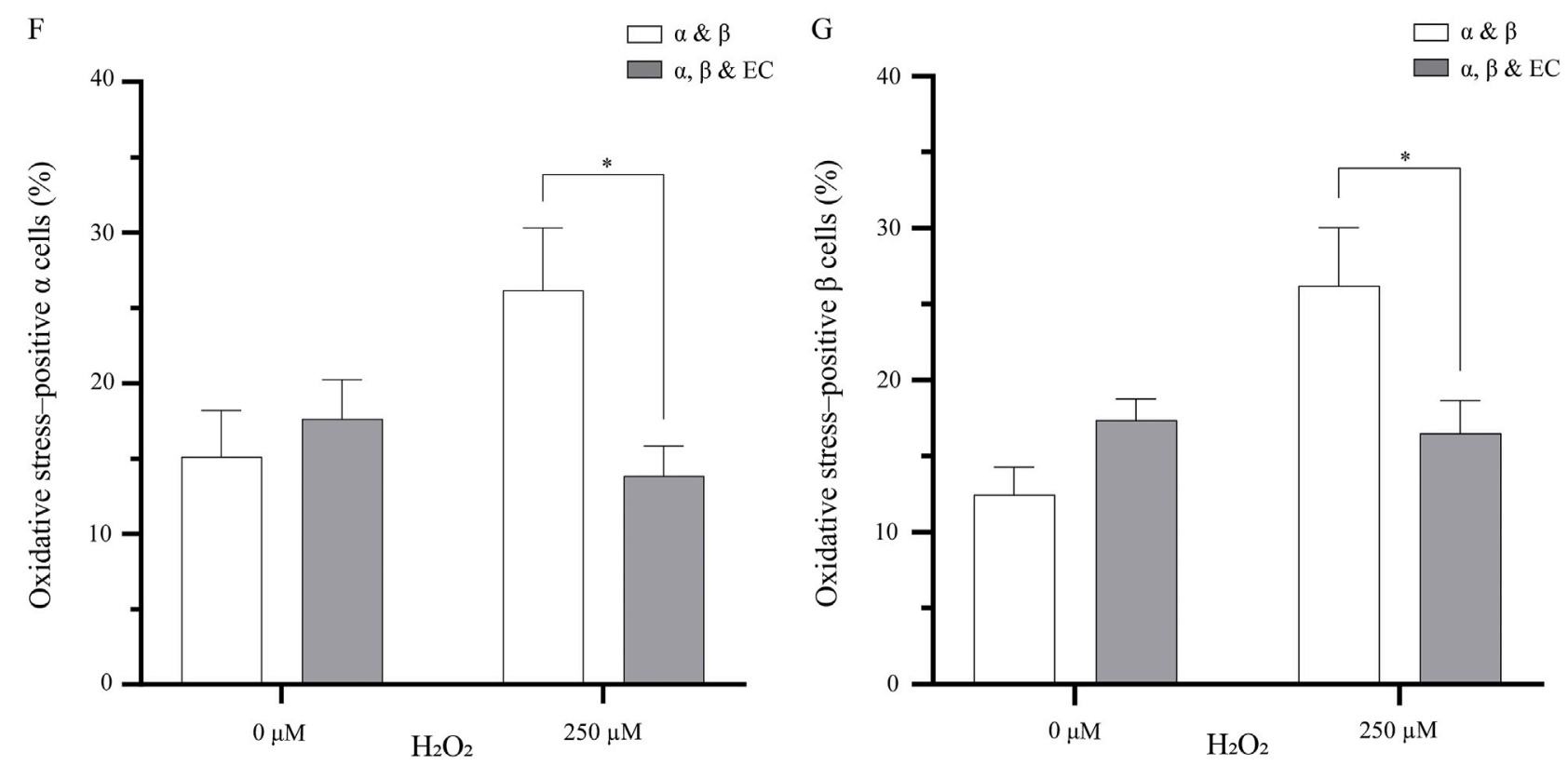

FIGURE 1 | The addition of endothelial cells in the pseudoislet reduces the oxidative stress in $\alpha$ and $\beta$ cells (A, B) Fluorescence imaging reveals ROS-positive cells in samples that were exposed to $250 \mu \mathrm{M} \mathrm{H}_{2} \mathrm{O}_{2}$, showing $\alpha$ cells (blue), $\beta$ cells (green) and ROS (grey) (C, D) Oxidative stress varies in pseudoislets with and without endothelial cells. A lower percentage of oxidative stress-positive cells are found in the pseudoislets including endothelial cells. Scale bars: 50 um (E) After 5 days in culture, the endothelial cells decrease oxidative stress ( $\left.{ }^{\star \star \star} p<0.001\right)$ (F) The presence of endothelial cells in the pseudoislet did not affect the percentage of oxidative stress-positive $\alpha$ cells in the basal media, however when induced by $\mathrm{H}_{2} \mathrm{O}_{2}$, a significant decrease of oxidative stress-positive $\alpha$ cells was seen ( ${ }^{*} p<0.04$ ) (G) The inclusion of endothelial cells in the pseudoislet reduced the percentage of oxidative stress-positive $\beta$ cells upon induction by $\mathrm{H}_{2} \mathrm{O}_{2}\left({ }^{*} p<0.04\right)$. Results are expressed as mean \pm SEM, and each data set includes twelve pseudoislets (n:12), and the experiment was repeated three times (N:3).

induced by $\mathrm{H}_{2} \mathrm{O}_{2}$, the presence of endothelial cells impacted how the $\alpha$ cells responded. Without endothelial cells in the pseudoislet, $\mathrm{H}_{2} \mathrm{O}_{2}$ increased the percentage of oxidative stress-positive $\alpha$ cells to $26.2 \%$, but with endothelial cells in the pseudoislet, this was reduced to 13.8\% ( $p<0.04$; Figure 1F; N:3, n:12). The $\beta$ cells had comparable percentages of oxidative stress-positive cells in the basal condition without $\mathrm{H}_{2} \mathrm{O}_{2}$ regardless of the presence of endothelial cells (17.4\% with vs $12.5 \%$ without endothelial cells; Figure 1G; N:3, n:12). However, when oxidative stress was induced by $\mathrm{H}_{2} \mathrm{O}_{2}$, the presence of endothelial cells reduced the percentage of oxidative stress-positive $\beta$ cells from 26.2 to $16.5 \%$ (Figure 1G; $p<0.04 ; \mathrm{N}: 3$, $\mathrm{n}: 12)$. 


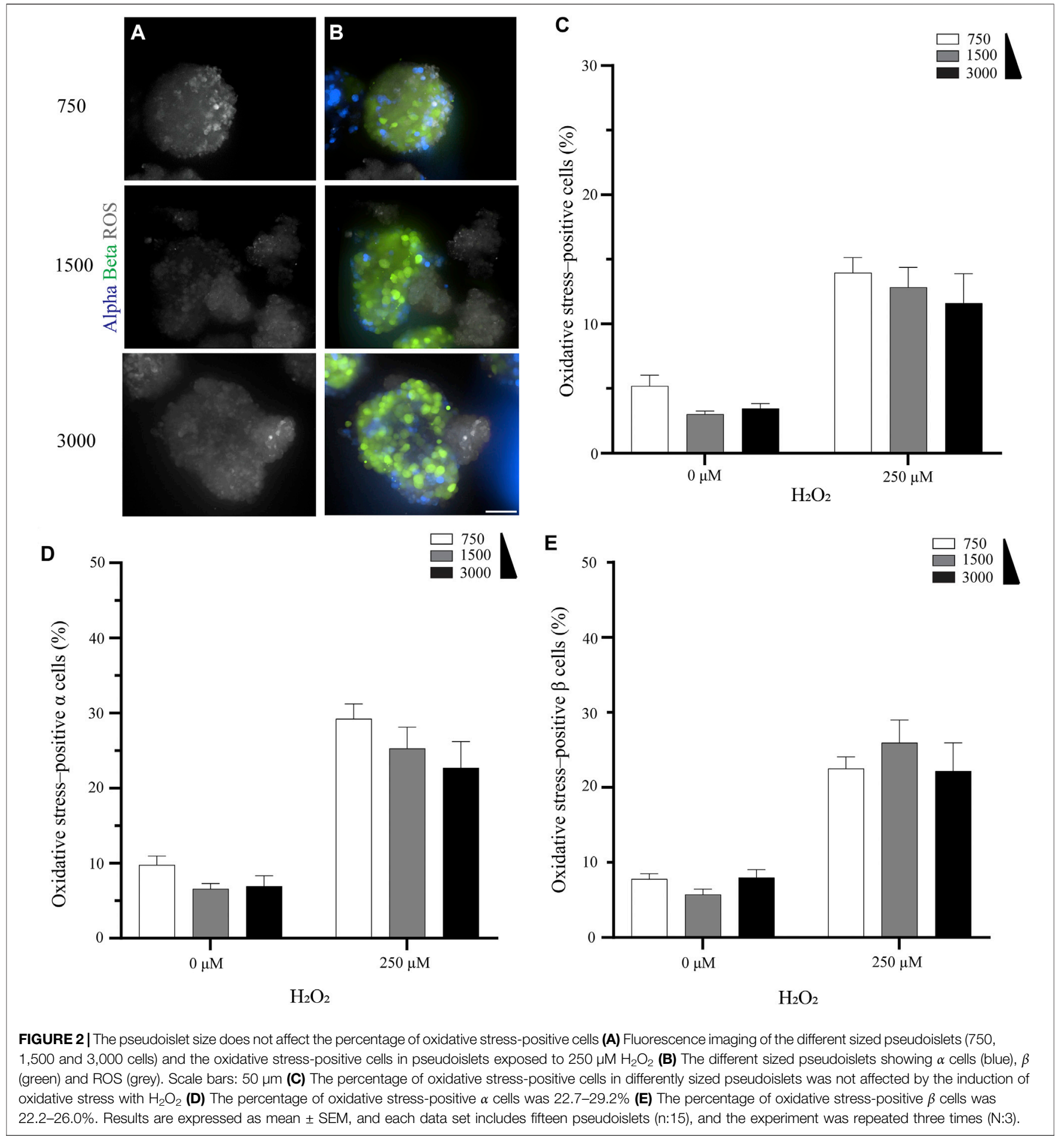

The Pseudoislet Size does not Affect the Percentage of Oxidative Stress-Positive

\section{Cells}

Having determined that endothelial cells in the pseudoislet protected both $\alpha$ and $\beta$ cells from oxidative stress induced by $\mathrm{H}_{2} \mathrm{O}_{2}$, we then asked whether the size of the pseudoislet could play a role, as our previous research showed that more endothelial cells were incorporated into the pseudoislet when the size increased (Wieland et al., 2020). To study this, we generated three differently sized pseudoislets with $750,1,500$ or 3,000 cells, all with the composition of $6.7 \% \alpha$ cells, $60 \% \beta$ cells and $33.3 \%$ endothelial cells.

Overall, the size of the pseudoislet had no apparent effect on the oxidative stress (Figures 2A,B). This result was confirmed when we quantified the percentage of oxidative stress-positive 

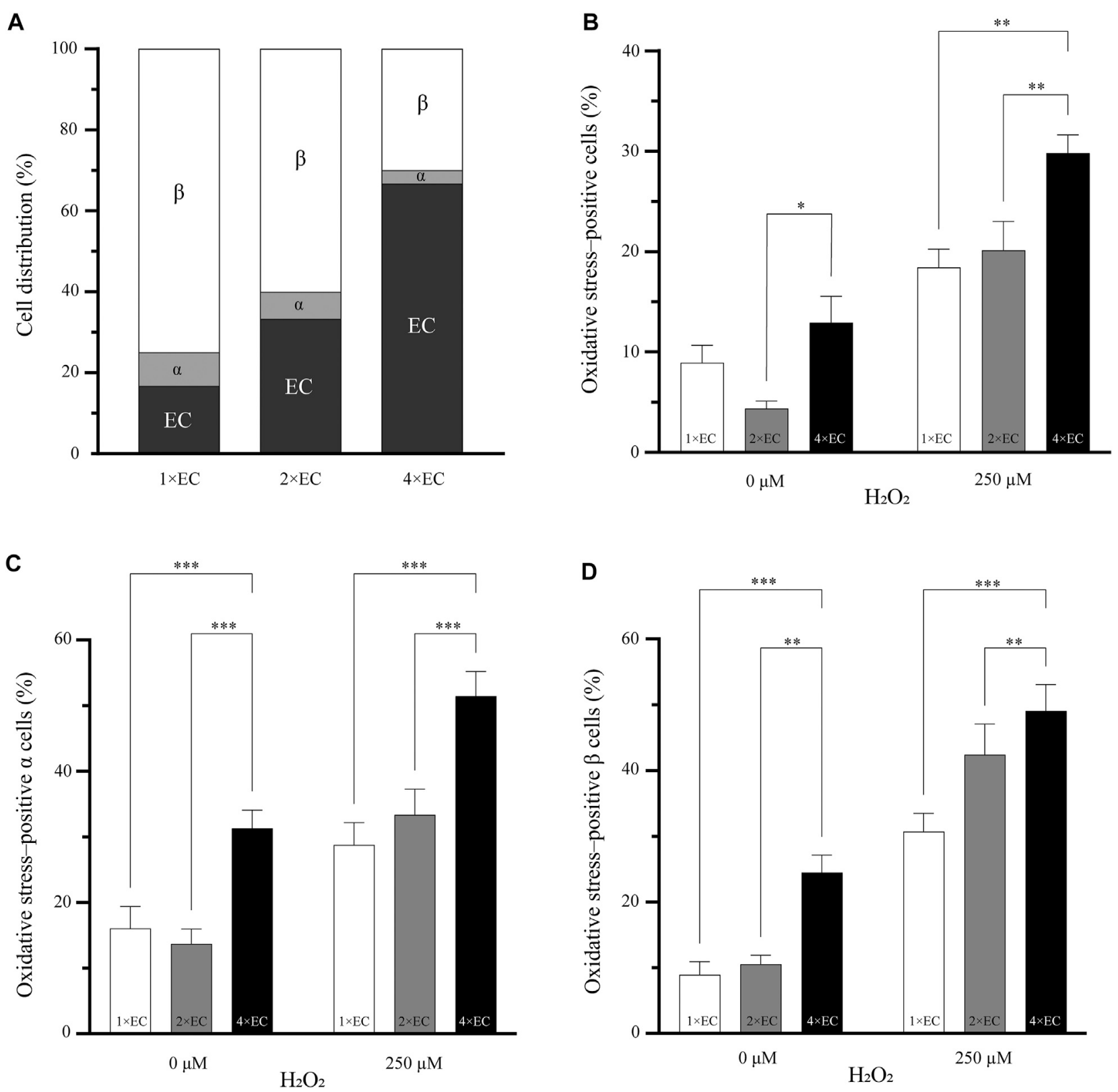

FIGURE 3 | Increasing the number of endothelial cells does decrease the percentage of oxidative stress-positive cells (A) Three different seeding conditions of endothelial cells were used to understand if the number of endothelial cells can influence the oxidative stress in the pseudoislet. The cell ratio between $\alpha$ and $\beta$ remained the same in all three conditions (B) The two pseudoislets $(1 x$ and $2 x)$ with the fewest endothelial cells had a significantly lower number of oxidative stress-positive cells than the $4 \times$ pseudoislet with the induction of oxidative stress $\left({ }^{\star} p<0.03,{ }^{\star \star} p<0.008\right)$ (C, D) Looking at the $\alpha$ and $\beta$ cells, there were significantly more oxidative stress-positive cells $\left({ }^{\star \star} p<0.01,{ }^{\star \star \star} p<0.001\right)$ in the $4 \times$ pseudoislets. Results are expressed as mean \pm SEM, and each data set includes twelve pseudoislets (n:12), and the experiment was repeated three times $(\mathrm{N}: 3)$.

cells. While the percentage increased when oxidative stress was induced by $\mathrm{H}_{2} \mathrm{O}_{2}$ (from $3.0-5.2 \%$ to $11.6-14.0 \%$ ), as would be expected, it was unaffected by the size of the pseudoislet (Figure 2C). No significant difference was measured between the pseudoislets comprising 750,1,500, or 3,000 cells in terms of the percentage of oxidative stress-positive $\alpha$ cells $(22.7-29.2 \%, p>0.18)$ or $\beta$ cells (22.2-26.0\%, $p>0.72$ ) (Figures 2D,E; N:3, n:15).

\section{The Number of Endothelial Cells does Affect the Percentage of Oxidative Stress-Positive Cells}

Our observation that endothelial cells reduced the oxidative stress experienced by the $\alpha$ and $\beta$ cells (Figure 1) prompted us to consider whether increasing the quantity of the endothelial cells could further enhance this effect. We began by generating 
pseudoislets with three different seeding ratios of endothelial cells: $17 \%(1 \times), 33 \%(2 \times)$ and $67 \%(4 \times)$. The total number of cells ( 1,500 cells per pseudoislet) and the ratio between $\alpha$ and $\beta$ cells ( 1 : 9, respectively) remained constant (Figure 3A).

Figure $3 \mathbf{B}$ shows the percentage of oxidative stress-positive cells in the pseudoislets with the different endothelial cell ratios of $1 \times, 2 \times$ and $4 \times$. In the basal condition (without oxidative stress induced by $\mathrm{H}_{2} \mathrm{O}_{2}$ ), the $2 \times$ pseudoislet had significantly lower oxidative stress compared to the $4 \times$ pseudoislet (4.3\% compared to $12.9 \% ; p<0.03$ ). With the induction of $\mathrm{H}_{2} \mathrm{O}_{2}$, the $4 \times$ pseudoislet had significantly more cells positive for oxidative stress than the $1 \times$ and $2 \times$ pseudoislets ( $29.8 \%$ compared to 18.4 and 20.1\%, respectively; $p<0.008$ ) (Figure 3B; N:3, n:12).

When looking at the percentage of oxidative stress-positive $\alpha$ (Figure 3C) and $\beta$ (Figure 3D) cells, there was also a significant difference between the $4 \times$ pseudoislet compared to the $1 \times$ and $2 \times$ pseudoislets. The lowest percentage of oxidative stress-positive $\alpha$ cells was found in the $1 \times(p<0.001)$ and $2 \times(p<0.001)$ pseudoislets, which was both in the basal condition and with induction of oxidative stress. The $1 \times$ pseudoislet had $28.7 \%$ oxidative stress-positive a cells, and the $2 \times$ pseudoislet had $33.4 \%$ oxidative stress-positive $\alpha$ cells, which was significantly lower than the $4 \times$ pseudoislet that had $51.4 \%$ oxidative stresspositive $\alpha$ cells upon induction by $\mathrm{H}_{2} \mathrm{O}_{2}$ (Figure 3C; $\mathrm{N}: 3, \mathrm{n}: 12$ ).

The lowest percentage of oxidative stress-positive $\beta$ cells was also in the $1 \times$ and $2 \times$ pseudoislets. The $1 \times$ pseudoislet had only $8.9 \%$ oxidative stress-positive $\beta$ cells in the basal condition without $\mathrm{H}_{2} \mathrm{O}_{2}$, and with the induction of $\mathrm{H}_{2} \mathrm{O}_{2}$, this increased to $30.7 \%$. Both conditions had a significantly lower number of oxidative stress-positive $\beta$ cell than the $4 \times$ pseudoislet (Figure 3D; $p<0.001$; $\mathrm{N}: 3$, n:12). Similar findings were also observed in the $2 \times$ pseudoislet, where the percentage of oxidative stress-positive $\beta$ cells was significantly lower both with or without $\mathrm{H}_{2} \mathrm{O}_{2}$ compared to the $4 \times$ pseudoislet (Figure 3D; $p<0.01 ; \mathrm{N}: 3, \mathrm{n}: 12$ ).

In summary, we found that the number of endothelial cells in the pseudoislet affected the cells' oxidative stress. To our surprise, it was not that more endothelial cells enhanced the effect of reducing oxidative stress-positive cells. Instead, we saw that fewer endothelial cells ( $1 \times$ pseudoislet) resulted in the fewest oxidative stress-positive cells. These results suggested that the composition of the pseudoislet may be the leading factor in reducing oxidative stress. Since the $1 \times$ pseudoislet had more $\alpha$ cells compared to the $4 \times$ pseudoislet, we went on to investigate the role of $\alpha$ cells in reducing oxidative stress.

\section{The Incretin GLP-1 that is Secreted by the $\alpha$ Cells Reduce Oxidative Stress}

Given these findings, we were interested to know whether the $\alpha$ cells played a role in protecting against oxidative stress in the pseudoislet. Until this point, we had kept the ratio between the $\alpha$ and $\beta$ cells constant while modulating the prevalence of endothelial cells and overall pseudoislet size. Now we created two different conditions of pseudoislets: one with $6.7 \% \alpha$ cells, $60 \% \beta$ cells and $33.3 \%$ endothelial cells (ABEC), and one with $0 \% \alpha$ cells, $66.6 \% \beta$ cells and $33.3 \%$ endothelial cells (BEC).

Overall, the presence of $\alpha$ cells strongly impacted the oxidative stress in the pseudoislet. In the basal condition (without $\mathrm{H}_{2} \mathrm{O}_{2}$ ), adding $\alpha$ cells reduced the percentage of cells positive for oxidative stress from 13.0 to $4.5 \%$ ( $p<0.001$; Figure $4 \mathrm{~A} ; \mathrm{N}: 4, \mathrm{n}: 16)$. When $\mathrm{H}_{2} \mathrm{O}_{2}$ induced oxidative stress, this effect was even more pronounced, and the presence of $\alpha$ cells reduced the percentage of cells positive for oxidative stress from 18.8 to $8.8 \%(p<0.001)$.

To seek a biological basis of this effect, we looked at the glucagon like-peptide 1 (GLP-1), which is secreted by the $\alpha$ cells and has shown antioxidative properties. We wondered if a GLP-1 agonist could mimic the presence of $\alpha$ cells in the pseudoislet devoid of them. To test this hypothesis, we pre-incubated the pseudoislets with the GLP-1 agonist prior to induction of oxidative stress by $\mathrm{H}_{2} \mathrm{O}_{2}$. Overall, we found evidence that the GLP-1 agonist could replicate the effects of including the $\alpha$ cells in the pseudoislet. Without the GLP-1 agonist, the percentage of oxidative stresspositive cells induced by $\mathrm{H}_{2} \mathrm{O}_{2}$ increased from 13.0 to $18.8 \%$ in the pseudoislets without $\alpha$ cells. However, with the GLP-1 agonist, this increase was reduced (from 18.8 to $10.5 \%$ ), reaching levels statistically similar to those found in the pseudoislets with $\alpha$ cells (8.8\%; $p<0.001$; Figure 4B). Together, these results provide important insights into intercellular redox regulation by the composition of the pseudoislets.

\section{DISCUSSION}

The present study was designed to determine how the different cells in the pseudoislet have a supportive role in protecting against oxidative stress. To do this, we used three different cell lines, a (alpha TC-1), $\beta$ (INS1E) and endothelial (HUVEC) cells that we aggregated together in a three-dimensional suspension to form a pseudoislet. Our current pseudoislet model is limited by the reliance on only $\alpha$ cells and $\beta$ cells to represent the islet of Langerhans. This choice was considered carefully as this composition can match the functional level of a primary islet, and in addition, these cell lines are well-characterised (Kim et al., 2015; Skrzypek et al., 2018). Furthermore, the addition of endothelial cells confers complexity to the pseudoislet. It would nonetheless be interesting to consider including $\delta$ cells (making up $\sim 10 \%$ of the cell population in the islet) in future studies, as they are also known to interact with both $\alpha$ and $\beta$ cells (Brereton et al., 2015). These pseudoislets were cultured in microwells for up to 5 days. To induce oxidative stress, we exposed the pseudoislet to $\mathrm{H}_{2} \mathrm{O}_{2}$ for $1 \mathrm{~h}$ and subsequently detected the generated ROS with the CellROX Deep Red reagent before imaging with a fluorescence microscope. With this approach, we demonstrated that endothelial cells and $\alpha$ cells play an essential role in protecting the pseudoislet against oxidative stress.

Our interest began with the role of the endothelial cells, a cell type that is not only important in establishing a vasculature but also supports other cell types by synthesizing ECM proteins and secreting soluble factors (Cao and Wang, 2014). The addition of endothelial cells to $\beta$ cell cultures is known to increase their viability, insulin secretion, and oxidative stress protection (Brissova et al., 2006; Lau et al., 2012). There is also a link between endothelial cell dysfunction and oxidative stress in patients with type 1 or 2 diabetes stress, where an increase in oxidative stress in the endocrine cells has been reported (Hadi and Suwaidi, 2007; De Mattia et al., 2008). We showed that 

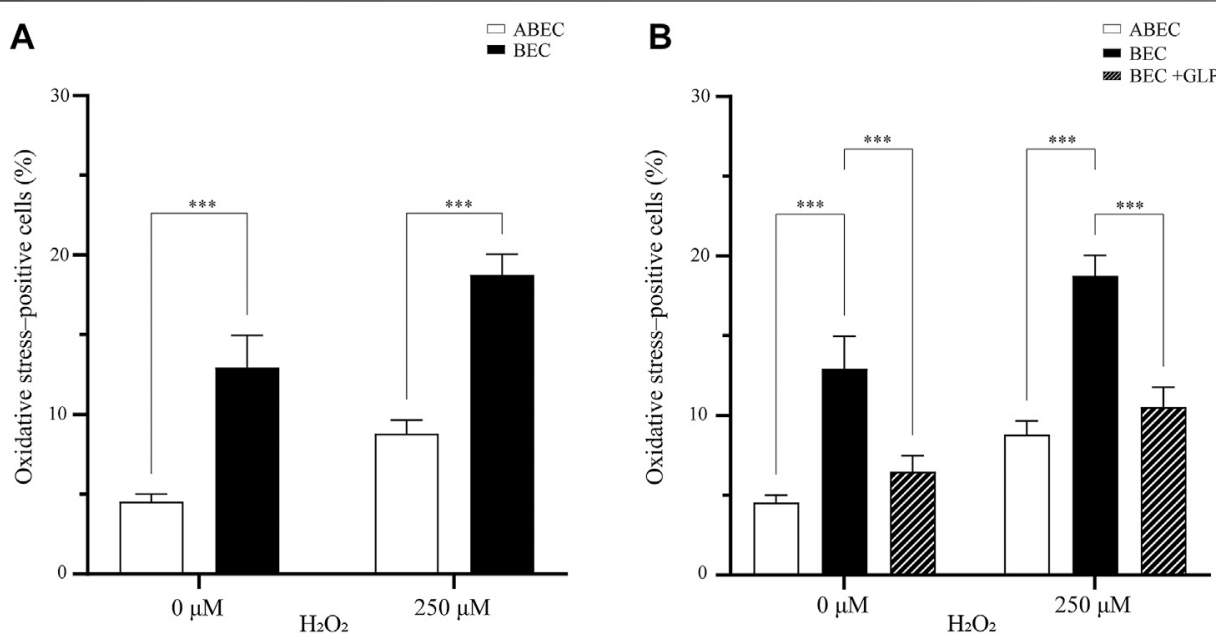

FIGURE 4 | GLP-1 reduces oxidative stress in the pseudoislet (A) Including $\alpha$ cells in the pseudoislet reduces the percentage of oxidative stress-positive cells from 13.0 to $4.5 \%$ in basal conditions and from 18.8 to $8.8 \%$ upon induction of oxidative stress by $\mathrm{H}_{2} \mathrm{O}_{2}\left({ }^{\star \star *} p<0.001\right)$ (B) The GLP-1 agonist mimicked the effect of having $\alpha$ cells present in the pseudoislet devoid of $\alpha$ cells, as it reduced the number of oxidative stress-positive cells from 18.8 to $10.5 \%$ (*** $p<0.001$ ). Results are expressed as mean \pm SEM, and each data set includes sixteen pseudoislets ( $\mathrm{n}: 16)$, and the experiment was repeated four times (N:4).

including endothelial cells in the pseudoislet significantly decreased the percentage of oxidative stress-positive cells from 7.6 to $3.6 \%$ upon induction of oxidative stress, a change of $32.1 \%$ (Figure 1E).

Looking at which cell types were affected by the inclusion of endothelial cells, we found that their addition to the coculture reduced the percentage of oxidative stress-positive $\alpha$ and $\beta$ cells by 34.5 and $38.6 \%$, respectively (Figures $\mathbf{1 F}, \mathbf{G}$ ). This protection is potentially consequential for $\beta$ cells, which are inadequate in antioxidant enzymes and are dysfunctional at high oxidative stress levels (Kaneto et al., 1999; Haskins et al., 2003; Stancill et al., 2019). The reduction of oxidative stress-positive cells can be attributed to the efficient antioxidative effect of the endothelial cells where various enzymes participate in protecting the endothelial cells against oxidative stress, e.g. superoxide dismutase (SOD), thioredoxin, catalase and glutathione peroxidase (Incalza et al., 2018; Sena et al., 2018; Alhayaza et al., 2020).

As far as improving the protective effect of endothelial cells against oxidative stress, many non-enzymatic compounds, such as vitamin $\mathrm{C}, \mathrm{D}$ - $\alpha$-tocopherol (vitamin $\mathrm{E}$ ), glutathione and $\alpha$-lipoic acid, have been supplemented to cells in in vitro and in vivo studies with a conclusive reduction in oxidative stress (Matough et al., 2012; Myasnikova et al., 2019). In our approach, we relied on the selfassembly process that forms the pseudoislet. Therefore, we challenged the pseudoislet by changing its size (total number of cells) and the ratio of endothelial cells to understand how they affected oxidative stress protection. Our results showed no significant benefit of changing the size of the pseudoislets from 750 to 3,000 cells per pseudoislet, as the number of oxidative stresspositive cells remained around $12.8 \%$ (Figure 2C). This was surprising, as previous studies have shown that larger pseudoislets incorporate more endothelial cells (Bosco et al., 2010; Wieland et al., 2020), suggesting that the protection conferred by the endothelial cells in our study was not directly correlated to their number.
We then examined how changing the ratio of the different cell types in the pseudoislet would affect oxidative stress levels. We focused on changing the prevalence of endothelial cells in the pseudoislet, which could explain if increasing their incorporation had a beneficial effect against oxidative stress, which was previously thought. Interestingly, despite the apparent protective effect of endothelial cells in the coculture, it was not that more endothelial cells gave a greater effect (Figure 3B). This was in agreement with our observation that the number of endothelial cells did not reduce oxidative stress. One possible explanation for this is that the $\beta$ and endothelial cells benefitted from an increased number of $\alpha$ cells in the condition with the fewest endothelial cells ( $1 \times$; Figure 3B). Our observation that both $\alpha$ and $\beta$ cells had the fewest cells positive for oxidative stress (28.7 and 30.7\%, respectively) in the condition with the most $\alpha$ cells $(1 \times$, Figures 3C,D) supported this explanation.

For an explanation of why the $\alpha$ cells might be protecting the $\beta$ and endothelial cells against oxidative stress, we looked at the incretin hormone GLP-1, which increases cellular levels of antioxidative enzymes, such as glutathione peroxidase and -reductase in $\beta$ cells, and inhibits oxidative stress in endothelial cells (Marchetti et al., 2012; Schisano et al., 2012; Fernández-Millán et al., 2016; Cai et al., 2018). GLP-1 was first found in the enteroendocrine L cells in the early 1980s. It is secreted at a low concentration in the fasting state but rapidly increases after food ingestion to affect blood glucose levels (Drucker, 2018). Previous studies had noted that $\alpha$ cells could secrete GLP-1 when metabolically stressed. The posttranslational processing of proglucagon regulates the formation of GLP-1 by the prohormone convertase $1 / 3$. Under normal (low stress) conditions, prohormone convertase $1 / 3$ is inactivated, and prohormone convertase 2 is active in the $\alpha$ cells, which generates the hormone glucagon (Sancho et al., 2017; Sandoval, 2020). This is the mechanism by which $\alpha$ cells play 
an essential role in providing antioxidant protection and controlling the glucose level.

In this study, we found that the inclusion or exclusion of $\alpha$ cells in the pseudoislet made a significant difference in the percentage of oxidative stress-positive cells. The pseudoislets with $\alpha$ cells had $4.5 \%$ oxidative stress-positive cells, while those without $\alpha$ cells had $13.0 \%$ (Figure 4A). We then wanted to determine whether this result may be explained by the fact that GLP-1 is essential for providing antioxidant protection. We were interested to learn that pseudoislets without $\alpha$ cells could be pre-incubated with the GLP-1 agonist, liraglutide, and that the percentage of oxidative stress-positive cells was statistically similar to having including the $\alpha$ cells (Figure 4B). This suggested that the protective effect of the $\alpha$ cells against the induction of oxidative stress could be attributed to their expression of GLP-1.

The underlying mechanism of how GLP-1 (or its agonist) protects against oxidative stress has been thoroughly described. Upon activation of the GLP-1 receptor, the protein kinase C pathway increases glutathione peroxidase and reductase in the $\beta$ cells and inhibits ROS-induced apoptosis by the associated activation of the PI3K/AKT signalling pathway (Buteau et al., 2006; FernándezMillán et al., 2016). The GLP-1 is also valuable for the endothelial cells as it can inhibit NADPH oxidase, which is elevated in oxidative stress (Oeseburg et al., 2010; Wang et al., 2013). Furthermore, GLP-1 enhanced eNOS and NO expression in endothelial cells to better protect against oxidative stress (Lim et al., 2017). Together, these data substantiate the importance of the support cells in the pseudoislet and explain the characteristic cell organization of the endocrine cells that we previously described (Wieland et al., 2020).

The results reported here shed new light on the beneficial effects of $\alpha$ and endothelial cells in protecting against oxidative stress in a three-dimensional coculture with $\beta$ cells. These findings can be applied in the setting of biomaterials for $\beta$ cell or islet encapsulation, where a GLP-1 agonist could be included to protect the cells from the stress induced by the material (Sthijns et al., 2021). The study also has implications for the aim of developing a cell-based therapy of $\beta$ cells from differentiated pluripotent stem cells and suggests that

\section{REFERENCES}

Alhayaza, R., Haque, E., Karbasiafshar, C., Sellke, F. W., and Abid, M. R. (2020). The Relationship between Reactive Oxygen Species and Endothelial Cell Metabolism. Front. Chem. 8, 1-21. doi:10.3389/fchem.2020.592688

Augsornworawat, P., Velazco-Cruz, L., Song, J., and Millman, J. R. (2019). A Hydrogel Platform for In Vitro Three Dimensional Assembly of Human Stem Cell-Derived Islet Cells and Endothelial Cells. Acta Biomater. 97, 272-280. doi:10.1016/j.actbio.2019.08.031

Bakker, S. J. L., IJzerman, R. G., Teerlink, T., Westerhoff, H. V., Gans, R. O. B., and Heine, R. J. (2000). Cytosolic Triglycerides and Oxidative Stress in Central Obesity: The Missing Link Between Excessive Atherosclerosis, Endothelial Dysfunction, and $\beta$-cell Failure?. Atherosclerosis 148, 17-21. doi:10.1016/ s0021-9150(99)00329-9

Ballian, N., and Brunicardi, F. C. (2007). Islet Vasculature as a Regulator of Endocrine Pancreas Function. World J. Surg. 31, 705-714. doi:10.1007/s00268006-0719-8

Berclaz, C., Szlag, D., Nguyen, D., Extermann, J., Bouwens, A., Marchand, P. J., et al. (2016). Label-free Fast 3D Coherent Imaging Reveals Pancreatic Islet Micro-Vascularization and Dynamic Blood Flow. Biomed. Opt. Express 7, 4569-4580. doi:10.1364/boe.7.004569 including both $\alpha$ and endothelial cells can be beneficial for successful transplantation into patients with type 1 diabetes (Orlando et al., 2014; Sthijns et al., 2018; Augsornworawat et al., 2019; Velazco-Cruz et al., 2019; Yoshihara et al., 2020).

\section{DATA AVAILABILITY STATEMENT}

The datasets presented in this study can be found at: https://doi. org/10.34894/F03MPH.

\section{AUTHOR CONTRIBUTIONS}

FW, MS, CB and VL contributed to conception and design of the study. FW and TG performed the experiments. FW performed the statistical analysis. FW wrote the first draft of the article. TG wrote sections of the article. All authors contributed to article revision, read, and approved the submitted version.

\section{FUNDING}

This project has received funding from the European Research Council (ERC) under the European Union's Horizon 2020 research and innovation programme (grant agreement No. 694801).

\section{ACKNOWLEDGMENTS}

This work was supported by the Core Facility Two-Photon Imaging, a core facility of the Interdisciplinary Center for Clinical Research (IZKF) Aachen within the Faculty of Medicine at RWTH Aachen University. The authors also thank Timo Rademakers (Maastricht University) for his technical assistance with the microscopy.

Bosco, D., Armanet, M., Morel, P., Niclauss, N., Sgroi, A., Muller, Y. D., et al. (2010). Unique Arrangement of - and -Cells in Human Islets of Langerhans. Diabetes 59, 1202, 1210. doi:10.2337/db09-1177

Brereton, M. F., Vergari, E., Zhang, Q., and Clark, A. (2015). Alpha-, Deltaand PP-Cells. J. Histochem. Cytochem. 63, 575-591. doi:10.1369/ 0022155415583535

Brissova, M., Shostak, A., Shiota, M., Wiebe, P. O., Poffenberger, G., Kantz, J., et al. (2006). Pancreatic Islet Production of Vascular Endothelial Growth Factor-A Is Essential for Islet Vascularization, Revascularization, and Function. Diabetes 55, 2974-2985. doi:10.2337/db06-0690

Buteau, J., Spatz, M. L., and Accili, D. (2006). Transcription Factor FoxO1 Mediates Glucagon-like Peptide-1 Effects on Pancreatic -Cell Mass. Diabetes 55, 1190-1196. doi:10.2337/db05-0825

Cai, X., She, M., Xu, M., Chen, H., Li, J., Chen, X., et al. (2018). GLP-1 Treatment Protects Endothelial Cells from Oxidative Stress-Induced Autophagy and Endothelial Dysfunction. Int. J. Biol. Sci. 14, 1696-1708. doi:10.7150/ijbs.27774

Cao, Z., and Wang, X. (2014). The Endocrine Role between $\beta$ Cells and Intra-islet Endothelial Cells [Review]. Endocr. J. 61, 647-654. doi:10.1507/endocri.ej14-0045

De Mattia, G., Bravi, M. C., Laurenti, O., Moretti, A., Cipriani, R., Gatti, A., et al. (2008). Endothelial Dysfunction and Oxidative Stress in Type 1 and Type 2 Diabetic Patients without Clinical Macrovascular Complications. Diabetes Res. Clin. Pract. 79, 337-342. doi:10.1016/j.diabres.2007.09.005 
Drucker, D. J. (2018). Mechanisms of Action and Therapeutic Application of Glucagonlike Peptide-1. Cel Metab. 27, 740-756. doi:10.1016/..cmet.2018.03.001

Fernández-Millán, E., Martín, M. A., Goya, L., Lizárraga-Mollinedo, E., Escrivá, F., Ramos, S., et al. (2016). Glucagon-like Peptide-1 Improves Beta-Cell Antioxidant Capacity via Extracellular Regulated Kinases Pathway and Nrf2 Translocation. Free Radic. Biol. Med. 95, 16-26. doi:10.1016/j.freeradbiomed.2016.03.002

Figliolini, F., Cantaluppi, V., De Lena, M., Beltramo, S., Romagnoli, R., Salizzoni, M., et al. (2014). Isolation, Characterization and Potential Role in Beta CellEndothelium Cross-Talk of Extracellular Vesicles Released from Human Pancreatic Islets. PLoS One 9, e102521. doi:10.1371/journal.pone.0102521

Gerber, P. A., and Rutter, G. A. (2017). The Role of Oxidative Stress and Hypoxia in Pancreatic Beta-Cell Dysfunction in Diabetes Mellitus. Antioxid. Redox Signaling 26, 501-518. doi:10.1089/ars.2016.6755

Hadi, H. A., and Suwaidi, J. A. (2007). Endothelial Dysfunction in Diabetes Mellitus. Vasc. Health Risk Manag. 3, 853-876.

Haskins, K., Bradley, B., Powers, K., Fadok, V., Flores, S., Ling, X., et al. (2003). Oxidative Stress in Type 1 Diabetes. Ann. N. Y. Acad. Sci. 1005, 43-54. doi:10.1196/annals.1288.006

Incalza, M. A., D’Oria, R., Natalicchio, A., Perrini, S., Laviola, L., and Giorgino, F. (2018). Oxidative Stress and Reactive Oxygen Species in Endothelial Dysfunction Associated with Cardiovascular and Metabolic Diseases. Vasc. Pharmacol. 100, 1-19. doi:10.1016/j.vph.2017.05.005

Ishibashi, Y., Matsui, T., Takeuchi, M., and Yamagishi, S.-i. (2010). Glucagon-like Peptide-1 (GLP-1) Inhibits Advanced Glycation End Product (AGE)-induced Up-Regulation of VCAM-1 mRNA Levels in Endothelial Cells by Suppressing AGE Receptor (RAGE) Expression. Biochem. Biophys. Res. Commun. 391, 1405-1408. doi:10.1016/j.bbrc.2009.12.075

Kaneto, H., Kajimoto, Y., Miyagawa, J., Matsuoka, T., Fujitani, Y., Umayahara, Y., et al. (1999). Beneficial Effects of Antioxidants in Diabetes: Possible protection of Pancreatic Beta-Cells against Glucose Toxicity. Diabetes 48, 2398-2406. doi:10.2337/diabetes.48.12.2398

Kim, S. M., Lee, E. J., Jung, H. S., Han, N., Kim, Y. J., Kim, T. K., et al. (2015). CoCulture of $\alpha$ TC- 6 Cells and $\beta$ TC-1 Cells: Morphology and Function. Endocrinol. Metab. 30, 92-97. doi:10.3803/enm.2015.30.1.92

Komatsu, H., Cook, C., Wang, C.-H., Medrano, L., Lin, H., Kandeel, F., et al. (2017). Oxygen Environment and Islet Size Are the Primary Limiting Factors of Isolated Pancreatic Islet Survival. PLoS One 12, e0183780. doi:10.1371/ journal.pone. 0183780

Lau, J., Svensson, J., Grapensparr, L., Johansson, A., and Carlsson, P.-O. (2012). Superior Beta Cell Proliferation, Function and Gene Expression in a Subpopulation of Rat Islets Identified by High Blood Perfusion. Diabetologia 55, 1390-1399. doi:10.1007/s00125-012-2476-6

Lim, D.-M., Park, K.-Y., Hwang, W.-M., Kim, J.-Y., and Kim, B.-J. (2017). Difference in Protective Effects of GIP and GLP-1 on Endothelial Cells According to Cyclic Adenosine Monophosphate Response. Exp. Ther. Med. 13, 2558-2564. doi:10.3892/etm.2017.4279

Liu, P., Song, J., Liu, H., Yan, F., He, T., Wang, L., et al. (2018). Insulin Regulates Glucagon-like Peptide-1 Secretion by Pancreatic Alpha Cells. Endocrine 62, 394-403. doi:10.1007/s12020-018-1684-3

Marchetti, P., Lupi, R., Bugliani, M., Kirkpatrick, C. L., Sebastiani, G., Grieco, F. A., et al. (2012). A Local Glucagon-like Peptide 1 (GLP-1) System in Human Pancreatic Islets. Diabetologia 55, 3262-3272. doi:10.1007/s00125-0122716-9

Matough, F. A., Budin, S. B., Hamid, Z. A., Alwahaibi, N., and Mohamed, J. (2012). The Role of Oxidative Stress and Antioxidants in Diabetic Complications. Squmj 12, 5-18. doi:10.12816/0003082

Myasnikova, D., Osaki, T., Onishi, K., Kageyama, T., Zhang Molino, B., and Fukuda, J. (2019). Synergic Effects of Oxygen Supply and Antioxidants on Pancreatic $\beta$-cell Spheroids. Sci. Rep. 9, 1802. doi:10.1038/s41598-01838011-6

Oeseburg, H., de Boer, R. A., Buikema, H., van der Harst, P., van Gilst, W. H., and Sillje', H. H. W. (2010). Glucagon-Like Peptide 1 Prevents Reactive Oxygen Species-Induced Endothelial Cell Senescence through the Activation of Protein Kinase A. Atvb 30, 1407-1414. doi:10.1161/atvbaha.110.206425

Olerud, J., Mokhtari, D., Johansson, M., Christoffersson, G., Lawler, J., Welsh, N., et al. (2011). Thrombospondin-1: An Islet Endothelial Cell Signal of Importance for -Cell Function. Diabetes 60, 1946-1954. doi:10.2337/db100277
Orlando, G., Gianello, P., Salvatori, M., Stratta, R. J., Soker, S., Ricordi, C., et al. (2014). Cell Replacement Strategies Aimed at Reconstitution of the $\beta$-Cell Compartment in Type 1 Diabetes. Diabetes 63, 1433-1444. doi:10.2337/db131742

Sancho, V., Daniele, G., Lucchesi, D., Lupi, R., Ciccarone, A., Penno, G., et al. (2017). Metabolic Regulation of GLP-1 and PC1/3 in Pancreatic $\alpha$-cell Line. PLoS One 12, e0187836. doi:10.1371/journal.pone.0187836

Sandoval, D. (2020). Updating the Role of $\alpha$-Cell Preproglucagon Products on GLP-1 Receptor-Mediated Insulin Secretion. Diabetes 69, 2238-2245. doi:10.2337/dbi19-0027

Schisano, B., Harte, A. L., Lois, K., Saravanan, P., Al-Daghri, N., Al-Attas, O., et al. (2012). GLP-1 Analogue, Liraglutide Protects Human Umbilical Vein Endothelial Cells against High Glucose Induced Endoplasmic Reticulum Stress. Regul. Peptides 174, 46-52. doi:10.1016/ j.regpep.2011.11.008

Sena, C. M., Leandro, A., Azul, L., Seiça, R., and Perry, G. (2018). Vascular Oxidative Stress: Impact and Therapeutic Approaches. Front. Physiol. 9, 1668. doi:10.3389/fphys.2018.01668

Skrzypek, K., Barrera, Y. B., Groth, T., and Stamatialis, D. (2018). Endothelial and Beta Cell Composite Aggregates for Improved Function of a Bioartificial Pancreas Encapsulation Device. Int. J. Artif. Organs 41, 152-159. doi:10.1177/0391398817752295

Stancill, J. S., Broniowska, K. A., Oleson, B. J., Naatz, A., and Corbett, J. A. (2019). Pancreatic $\beta$-cells Detoxify $\mathrm{H} 2 \mathrm{O} 2$ through the Peroxiredoxin/thioredoxin Antioxidant System. J. Biol. Chem. 294, 4843-4853. doi:10.1074/ jbc.ra118.006219

Sthijns, M. M. J. P. E., van Blitterswijk, C. A., and LaPointe, V. L. S. (2018). Redox Regulation in Regenerative Medicine and Tissue Engineering: The Paradox of Oxygen. J. Tissue Eng. Regen. Med. 12, 2013-2020. doi:10.1002/term.2730

Sthijns, M. M. J. P. E., Jetten, M. J., Mohammed, S. G., Claessen, S. M. H., de Vries, R. H. W., Stell, A., et al. (2021). Oxidative Stress in Pancreatic Alpha and Beta Cells as a Selection Criterion for Biocompatible Biomaterials. Biomaterials 267, 120449. doi:10.1016/j.biomaterials.2020.120449

Velazco-Cruz, L., Song, J., Maxwell, K. G., Goedegebuure, M. M., Augsornworawat, P., Hogrebe, N. J., et al. (2019). Acquisition of Dynamic Function in Human Stem Cell-Derived $\beta$ Cells. Stem Cel Rep. 12, 351-365. doi:10.1016/ j.stemcr.2018.12.012

Wang, D., Luo, P., Wang, Y., Li, W., Wang, C., Sun, D., et al. (2013). Glucagon-like Peptide-1 Protects against Cardiac Microvascular Injury in Diabetes via a cAMP/PKA/Rho-dependent Mechanism. Diabetes 62, 1697, 1708. doi:10.2337/ $\mathrm{db} 12-1025$

Wieland, F. C., Sthijns, M. M. J. P. E., Geuens, T., van Blitterswijk, C. A., and LaPointe, V. L. S. (2021). The Role of Alpha Cells in the Self-Assembly of Bioengineered Islets. Tissue Eng. A 27, 1055-1063. doi:10.1089/ten.tea.2020.0080

Xu, E., Kumar, M., Zhang, Y., Ju, W., Obata, T., Zhang, N., et al. (2006). Intra-islet Insulin Suppresses Glucagon Release via GABA-GABAA Receptor System. Cel Metab. 3, 47-58. doi:10.1016/j.cmet.2005.11.015

Yoshihara, E., O'Connor, C., Gasser, E., Wei, Z., Oh, T. G., Tseng, T. W., et al. (2020). Immune-evasive Human Islet-like Organoids Ameliorate Diabetes. Nature 586, 606-611. doi:10.1038/s41586-020-2631-z

Conflict of Interest: The authors declare that the research was conducted in the absence of any commercial or financial relationships that could be construed as a potential conflict of interest.

Publisher's Note: All claims expressed in this article are solely those of the authors and do not necessarily represent those of their affiliated organizations, or those of the publisher, the editors and the reviewers. Any product that may be evaluated in this article, or claim that may be made by its manufacturer, is not guaranteed or endorsed by the publisher.

Copyright (๐ 2021 Wieland, Sthijns, Geuens, van Blitterswijk and LaPointe. This is an open-access article distributed under the terms of the Creative Commons Attribution License (CC BY). The use, distribution or reproduction in other forums is permitted, provided the original author(s) and the copyright owner $(s)$ are credited and that the original publication in this journal is cited, in accordance with accepted academic practice. No use, distribution or reproduction is permitted which does not comply with these terms. 